\title{
STAVOVI I ZNANJE ZDRAVSTVENIH DJELATNIKA O PRIMJENI PRAKSE ZASNOVANE NA DOKAZIMA U RADIOLOGIJI
}

\author{
Martina Jurilj, Ana Jerković, Josip Šimić \\ Fakultet zdravstvenih studija Sveučilišta u Mostaru
}

Rad je primljen 24.10.2020.. Rad je recenziran 29.10.2020. Rad je prihvaćen 19.11.2020.

\section{SAŽETAK}

Uvod: Praksa utemeljena na dokazima u radiologiji je integracija najboljih dostupnih istraženih dokaza u radiološku primjenu. To uključuje pitanja povezana s tehnologijom, kliničkom radiologijom i kliničkom medicinom

Cilj: Cilj ovog istraživanja bio je ispitati razlike stupnja znanja i stavova te utvrditi razlike prepreka primjene prakse zasnovane na dokazima u radiologiji između Kliničkog zavoda za radiologiju Sveučilišne kliničke bolnice Mostar i Odjela za radiološku dijagnostiku Opće bolnice Pula.

Metode i ispitanici: Istraživanju su pristupili prvostupnici i magistri radiološke tehnologije te liječnici specijalisti radiologijekoji su samostalno ispunili upitnike. Provedeno je presječno istraživanje u Sveučilišnoj kliničkoj bolnici Mostar na Kliničkom zavodu za radiologiju te u Općoj bolnici Pula na Odjelu za radiološku dijagnostiku.

Rezultati: Ovo istraživanje upućuje na činjenicu da je većina radiološkog osoblja obiju bolnica imala pozitivan stav prema radiologiji zasnovanoj na dokazima. Razumijevanje pojmova koji se koriste u radiologiji zasnovanoj na dokazima bilo je povezano s primjenom iste. Čak 60 \% ispitanika mostarske bolnice potvrdno je odgovorilo da su za vrijeme svog školovanja učili osnove za pretraživanje informacija o primjeni dokaza u praksi, dok je na isto pitanje u pulskoj bolnici potvrdno odgovorilo $46,67 \%$ ispitanika.

Zaključak: Većina radiološkog osoblja obiju bolnica imala je pozitivan stav prema radiologiji zasnovanoj na dokazima. Primjenom medicine utemeljene na dokazima povezuju se individualna klinička zapažanja i iskustva s najboljim znanstvenim dokazima dobivenih kliničkim istraživanjima.

Ključne riječi: Stavovi i znanja, radiologija, praksa zasnovana na dokazima

Osoba za razmjenu informacija:

Ana Jerković, magistar radiološke tehnologije

E-mail: ajerkovic97@gmail.com 


\section{UVOD}

Medicina utemeljena na dokazima (engl. EBM EvidenceBased Medicine) bilježi svoje početke polovinom 19. stoljeća te označava savjesnu, nedvojbenu i kritičku primjenu najboljega mogućeg dokaza u donošenju odluka o skrbi za pojedinog bolesnika(1). Postoji mnogo istraživanja iz svih područja biomedicinskih i zdravstvenih znanosti koja su dostupna, ali često nisu kritički provjerena i ocijenjena. Zbog toga je važno razumijevanje evolucije načina pregleda literature, od jednostavnog pregleda sve do sustavnih pregleda kao ključnih elemenata za informiranje o odlučivanju (2-4).

Praksa utemeljena na dokazima u radiologiji je integracija najboljih dostupnih istraženih dokaza u radiološku primjenu. To uključuje pitanja povezana s tehnologijom, kliničkom radiologijom i kliničkom medicinom (5). Sukladno tome, medicina zasnovana na dokazima se prvi put definira 1992. kao „Medicina zasnovana na dokazima je savjesna, nedvojbena i kritička primjena najboljeg mogućeg dokaza u donošenju odluka o skrbi za pojedinog bolesnika“ $(5,6)$. To bi u radiologiji značilo aktivno traženje novih dokaza u struci kako bi se profesionalnost uskladila s novim saznanjima te u skladu s tim provodila visoka kvaliteta usluga u radiologiji $(7,8)$. Praksa zasnovana na dokazima u radiologiji postaje sve izraženija metoda unapređenja znanja (9). Radiologija je brzo razvijajuća grana medicine u kojoj je neprekidan tehnološki napredak. Kako bi se te promjene što bolje prihvatile, praksa zasnovana na dokazima postaje sve bitnija za kliničku i akademsku primjenu (10). Radiolozi se često nalaze u situaciji gdje odlučuju o najkompatibilnijoj metodi snimanja za pacijenta, uzimajući u obzir rizike kojima se pacijenti izlažu te kliničko pitanje. Također, pregledi intervencijske radiologije su alternativa ili velika pomoć složenim kirurškim zahvatima (11). Ostalo medicinsko osoblje se savjetuje $s$ radiolozima radi najrelevantnijeg mišljenja o pregledu, zbog čega je jako bitno da je to mišljenje radiologa zasnovano na dokazima. Klinička praksa utemeljena na dokazima predstavlja povezivanje osobnoga kliničkog iskustva liječnika i sustava vrijednosti bolesnika s najboljim mogućim dokazom iz medicinske literature (1). Stoga, jednostavna dostupnost dokaza, sposobnost for- muliranja pitanja koje je moguće odgovoriti, vještine u tehnikama istraživanja, kritička procjena na literaturu i povezivanje kliničkog konteksta i problema sa dokazima je vrlo važno za dobru radiološku praksu $(12,13)$. Uobičajeno, u radiologiji primjena prakse zasnovane na dokazima nije standard (14-16). Situacija je podjednaka i u ostalim zdravstvenim struka$\mathrm{ma}(17,18)$. Saznanja medicinskih istraživanja govore kako je velika razlika između medicine zasnovane na dokazima i stvarne kliničke skrbi te da nedostaje njezina primjena $(19,20)$.

U istraživanju provedenom 2012. godine od strane Christian MedicalCollege-a u bolnicama na području južne Indije sudjelovalo je 80 ispitanika koji su zaposleni kao radiolozi ili radiološki tehnolozi(21). Ovo istraživanje imalo je za cilj procjenu stava, znanja i prepreka u primjeni prakse zasnovane na dokazima u radiologiji te kako ih percipiraju djelatnici radiologije na području južne Indije. Sve je veća svijest i potreba za uključivanjem radiologije temeljene na dokazima u nastavni plan i program i učiniti ga sastavnim dijelom studija radiologije u cijelom svijetu. Smatra se da je uključivanje prakse utemeljene na dokazima u radiologiji jasan način zadržavanja radiologa u akademskim institucijama $(22,23)$. Ovo istraživanje je jasno pokazalo da je većina djelatnika imala pozitivan stav prema radiologiji zasnovanoj na dokazima te da je odnos među kolegama imao jako velik utjecaj na to. Također, razumijevanje izraza koji se koriste u literaturi zasnovanoj na dokazima pridonijelo je pozitivnom stavu prema radiologiji zasnovanoj na dokazima te je rezultiralo snažnim uvjerenjem da će bolja skrb o pacijentima biti moguća prakticiranjem iste. Znanje i vještine potrebne za kritičko prosuđivanje prakse zasnovane na dokazima često se uče kroz samostalne tečajeve koji nisu u sklopu posla. Jedno prijašnje istraživanje pokazalo je da se tijekom školovanja premalo obrađuje ta tema (24). Time su zaključili da je potrebno obrazovanje u kojem je uključena radiologija zasnovana na dokazima(5). Također je slično istraživanje provedeno u na području Wessexa u Engleskoj 1998. godine, gdje je sudjelovalo 302 sudionika zaposlenih kao doktori opće prakse(5). Ispitanici su uglavnom imali pozivan stav prema medicini zasnovanoj na dokazima i složili 
se da njezina praksa poboljšava skrb o pacijentima. Glavna uočena prepreka bila je nedostatak osobnog vremena. Smatrali su da je najprikladniji način za prelazak na opću praksu zasnovanu na dokazima, korištenje smjernica ili prijedloga koje su razvili kolege. Poticanje i poboljšanje pristupa sažecima dokaza, umjesto proučavanja svih literatura, olakšao bi primjenu opće prakse zasnovane na dokazima. U istraživačkom radu Evidence-basedpracticeinradiology M. Dias i suradnika provedenom 2013. godine, u kojemu je sudjelovalo 40 radioloških tehnologa na području Algavre(Portugal), opisano je kako većina radioloških tehnologa ne primjenjuje praksu utemeljenu na dokazima (25). Međutim, temeljno znanje ove tematike sugerira njezinu primjenu kako bi se bolje razvile vještine, znanje te bolji pristup radu (25). Cilj ovog istraživanja bio je otkriti razlike stupnja znanja i stavova te utvrditi razlike prepreka primjene prakse zasnovane na dokazima u radiologiji između Kliničkog zavoda za radiologiju Sveučilišne kliničke bolnice Mostar i Odjela za radiološku dijagnostiku Opće bolnice Pula.

\section{METODE I ISPITANICI Ispitanici}

Istraživanju su pristupili prvostupnici i magistri radiološke tehnologije te liječnici specijalisti radiologijekoji su samostalno ispunili upitnike. Sveukupno je pristupilo 36 ispitanika, no šestero je isključeno zbog nepotpuno ispunjenog upitnika.

\section{Metode}

Provedeno je presječno istraživanje u Sveučilišnoj kliničkoj bolnici Mostar na Kliničkom zavodu za radiologiju te u Općoj bolnici Pula na Odjelu za radiološku dijagnostiku. Etičko povjerenstvo Sveučilišne kliničke bolnice Mostar odobrilo je provođenje istraživanja 28 srpnja 2020., dok je Etičko povjerenstvo Opće bolnice Pula tu odluku donijelo 08. rujna 2020. Sukladno tome, istraživanje se provodilo od 20. rujna do 10. listopada 2020. Za potrebe ovog istraživanja kao mjerni instrument korišteni su preuzeti prilagođeni upitnici. Upitnici su prethodno korišteni u radu Evidence-based practice in radiology: Knowledge, attitude and perceived barriers to practice among residents in radiology objavljenom u European Journal of Radiology 2013. godine (18).

Statistička obrada

Prikupljeni podaci pohranili su se u MS Excel bazi podataka, a za statističku analizu prikupljenih podataka koristio se programski sustav Program R. $\mathrm{U}$ analizi podataka koristile su se metode deskriptivne statistike te neparametrijske statističke metode. Kategoričke varijable opisane su preko frekvencija, a kontinuirane preko deskriptivno-statističkih pokazatelja tih varijabli (aritmetička sredina, standardna devijacija, minimum, maksimum, koeficijent asimetričnosti, koeficijent spljoštenosti). Za usporedbu učestalosti pojavnosti varijabli korišten je hi-kvadrat test, za razlike između dvije grupe ispitanika na jednoj varijabli Mann-Whitneyjev U test.

\section{REZULTATI}

U istraživanju sudjelovalo ukupno 14 muškaraca, od toga 9 u Mostaru i 5 u Puli te 16 žena, od toga 6 u Mostaru i 10 u Puli. U istraživanju su iz pulske bolnice sudjelovale samo osobe s preddiplomskim studijem, dok je iz bolnice u Mostaru sudjelovalo po 7 sudionika s preddiplomskim i poslijediplomskim studijem te 1 sudionik s diplomskim studijem.

Kako bi se ispitale karakteristike dobi sudionika, vremena proteklog od završetka studija te duljine rada u struci, izračunati su deskriptivno-statistički pokazatelji tih varijabli. Ti se pokazatelji nalaze u Tablici 1. Prema koeficijentima asimetričnosti i spljoštenosti vidljivo je da se varijable ne distribuiraju normalno, budući da ti koeficijenti izlaze iz raspona od 1.

Tablica 1. Karakteristike ispitanika

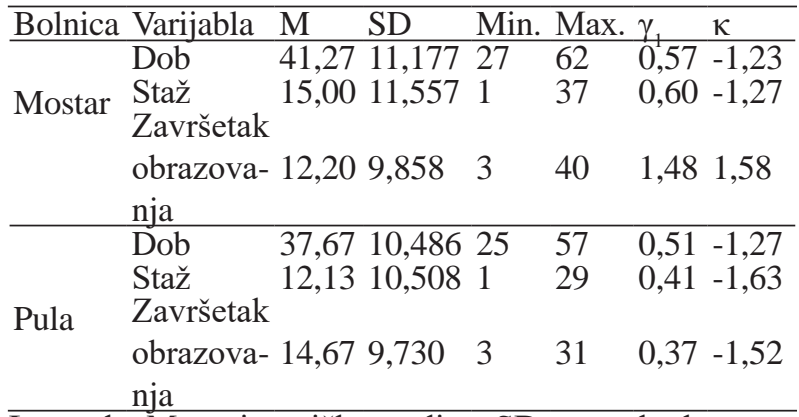

Legenda: M - aritmetička sredina, SD - standardna devijacija, Min. - minimum, Max. - maksimum, $\gamma_{1}-$ koeficijent asimetričnosti, $\kappa$ - koeficijent spljoštenosti. 
Kako bi se ispitale karakteristike varijabli vezanih uz pouzdanje u sposobnosti, izračunati su deskriptivno-statistički pokazatelji tih varijabli.Prema koeficijentima asimetričnosti i spljoštenosti vidljivo je da se 4.a) pitanje (i u Mostaru i u Puli), 4.b) pitanje (samo u Mostaru), 4.d) pitanje (i u Mostaru i u Puli), 4.g) pitanje (samo u Mostaru), 4.h) pitanje (samo u Mostaru), 4.i) pitanje (samo u Puli), 4.k) pitanje (samo u Puli) te 4.l) pitanje (i u Mostaru i u Puli) ne distribuiraju normalno, budući da ti koeficijenti izlaze iz raspona od 1. Stoga bi se nad tim varijablama trebale primijeniti neparametrijske statističke metode. Međutim, zbog male veličine uzorka, neparametrijske metode će ionako biti primijenjene na svim varijablama. Distribucije ostalih varijabli nisu značajno odstupale od normalne distribucije.

Tablica 2. Stavovi vezani uz ocjenu svoje sposobnosti.

\begin{tabular}{|c|c|c|c|c|c|c|c|}
\hline Bolnica & Varijabla & $M$ & $S D$ & Min. & Max. & $\gamma_{1}$ & $\kappa$ \\
\hline \multirow{12}{*}{ Mostar } & 4.a) pitanje & 2,27 & 0,458 & 2 & 3 & 0,95 & $-1,16$ \\
\hline & 4.b) pitanje & 2,27 & 0,704 & 1 & 3 & $-0,35$ & $-1,12$ \\
\hline & 4.c) pitanje & 2,20 & 0,561 & 1 & 3 & 0,09 & $-0,48$ \\
\hline & 4.d) pitanje & 2,20 & 0,414 & 2 & 3 & 1,35 & $-0,17$ \\
\hline & 4.e) pitanje & 2,20 & 0,561 & 1 & 3 & 0,09 & $-0,48$ \\
\hline & 4.f) pitanje & 2,07 & 0,594 & 1 & 3 & 0,00 & $-0,39$ \\
\hline & 4.g) pitanje & 1,67 & 0,816 & 1 & 3 & 0,60 & $-1,33$ \\
\hline & 4.h) pitanje & 1,67 & 0,816 & 1 & 3 & 0,60 & $-1,33$ \\
\hline & 4.i) pitanje & 2,27 & 0,594 & 1 & 3 & $-0,07$ & $-0,82$ \\
\hline & 4.j) pitanje & 2,33 & 0,617 & 1 & 3 & $-0,25$ & $-0,96$ \\
\hline & 4.k) pitanje & 2,47 & 0,640 & 1 & 3 & $-0,65$ & $-0,79$ \\
\hline & 4.1) pitanje & 2,53 & 0,516 & 2 & 3 & $-0,12$ & $-2,11$ \\
\hline \multirow{12}{*}{ Pula } & 4.a) & 2,33 & 0,488 & 2 & 3 & 0,64 & $-1,69$ \\
\hline & 4.b) pitanje & 2,13 & 0,640 & 1 & 3 & $-0,08$ & $-0,79$ \\
\hline & 4.c) pitanje & 2,20 & 0,561 & 1 & 3 & 0,09 & $-0,48$ \\
\hline & 4.d) pitanje & 2,07 & 0,458 & 1 & 3 & 0,28 & 1,27 \\
\hline & 4.e) pitanje & 2,00 & 0,535 & 1 & 3 & 0,00 & 0,27 \\
\hline & 4.f) pitanje & 2,00 & 0,535 & & 3 & 0,00 & 0,27 \\
\hline & 4.g) pitanje & 1,67 & 0,617 & 1 & 3 & 0,25 & $-0,96$ \\
\hline & 4.h) pi & 1,73 & 0,594 & & 3 & 0,07 & $-0,8$ \\
\hline & 4.i) $\mathrm{p}$ & 2,20 & 0,414 & 2 & 3 & 1,35 & $-0,1$ \\
\hline & 4.j) & 2,27 & 0,704 & 1 & 3 & $-0,35$ & $-1,12$ \\
\hline & & 2,27 & 0,799 & 1 & 3 & $-0,45$ & $-1,40$ \\
\hline & 4.1) & 2,47 & 0,516 & 2 & 3 & 0,12 & $-2,11$ \\
\hline
\end{tabular}

Legenda: $M$ - aritmetička sredina, $S D$ - standardna devijacija, Min. - minimum, Max. - maksimum, $\gamma_{1}-$ koeficijent asimetričnosti, $\kappa$ - koeficijent spljoštenosti.

$\mathrm{U}$ ovom istraživanju izračunat je ukupan rezultat na obuci i obrazovanju zbrajanjem varijabli vezanih uz obuku i obrazovanje, ukupan rezultat na pouzdanju u sposobnosti zbrajanjem varijabli vezanih uz pouzdanje u sposobnosti te ukupan rezultat na dostupnosti i podršci zbrajanjem varijabli vezanih uz dostupnost i podršku.

Kako bi se ispitale karakteristike tih ukupnih rezultata, izračunati su njihovi deskriptivno-statistički pokazatelji, koji se nalaze u Tablici 3. Prema koeficijentima asimetričnosti i spljoštenosti vidljivo je da se obuka i obrazovanje (i u Mostaru i u Puli), dostupnost i podrška (samo u Mostaru) te pouzdanje $\mathrm{u}$ sposobnosti (samo u Puli) ne distribuiraju normalno, budući da ti koeficijenti izlaze iz raspona od $|1|$. Stoga bi se nad tim varijablama trebale primijeniti neparametrijske statističke metode. Međutim, zbog male veličine uzorka, neparametrijske metode će ionako biti primijenjene na svim varijablama. Distribucije ostalih varijabli nisu značajno odstupale od normalne distribucije.

Tablica 3. Usporedni stavovi vezani uz ocjenu svoje sposobnosti

\begin{tabular}{|c|c|c|c|c|c|c|c|}
\hline $\begin{array}{l}\text { Bolni- } \\
\text { ca }\end{array}$ & Varijabla & M & SD & Min. & Max. & $\gamma_{1}$ & $\kappa$ \\
\hline \multirow{4}{*}{ Mostar } & $\begin{array}{l}\text { Obuka i ob } \\
\text { razovanje }\end{array}$ & 10,33 & 2,870 & & 15 & $-0,21$ & $-1,07$ \\
\hline & $\begin{array}{l}\text { Dostu- } \\
\text { pnost i }\end{array}$ & 5,67 & 2,066 & 2 & 8 & $-0,65$ & $-1,04$ \\
\hline & podrška & & & & & & \\
\hline & $\begin{array}{l}\text { danje u } \\
\text { sposob- } \\
\text { nosti }\end{array}$ & 26,13 & 5,330 & 21 & 36 & 0,86 & $-0,91$ \\
\hline \multirow{3}{*}{ Pula } & $\begin{array}{l}\text { Obuka i } \\
\text { obrazo- } \\
\text { vanje }\end{array}$ & 10,73 & 2,963 & 6 & 15 & $-0,08$ & $-1,34$ \\
\hline & $\begin{array}{l}\text { Dostu- } \\
\text { pnost i } \\
\text { podrška }\end{array}$ & 4,43 & 1,272 & 2 & 6 & $-0,70$ & $-0,75$ \\
\hline & $\begin{array}{l}\text { Pouz- } \\
\text { danje u } \\
\text { sposob- } \\
\text { nosti }\end{array}$ & 25,33 & 4,435 & 20 & 36 & 1,05 & 0,11 \\
\hline
\end{tabular}

Legenda: $\mathrm{M}$ - aritmetička sredina, SD - standardna devijacija, Min. - miznimum, Max. - maksimum, $\gamma_{1}-$ koeficijent asimetričnosti, $\kappa$ - koeficijent spljoštenosti.

Kako bi se ispitale karakteristike odgovora na pitanje 4.a) i 4.i) ovisno o dihotomiziranoj varijabli odgovora na prvo pitanje (niski/visoki odgovori), izračunati su deskriptivno-statistički pokazatelji tih varijabli. Značajnost razlika između ove dvije skupine testirana je Mann-Whitneyjevim U testovima. Pokazalo se kako statistički značajne razlike ovisno o niskom/visokom odgovoru na 1. pitanje ne postoji niti kod pitanja 4.a): $\mathrm{U}=124 ; \mathrm{p}=, 55$, niti kod pitanja 4.i): $\mathrm{U}=124.5$; $\mathrm{p}=, 53$ (Tablica 4.).

Značajnost razlika između ove dvije skupine testirana je Mann-Whitneyjevim U testovi- 
ma. Pokazalo se kako statistički značajne razlike ovisno o niskom/visokom odgovoru na 1. Pitanje (Učila/o sam osnove za pretraživanje informacija o primjeni dokaza u praksi za vrijeme svog školovanja.) ne postoji niti kod pitanja 4.a): $\mathrm{U}=124 ; \mathrm{p}=, 55$, niti kod pitanja 4.i): $\mathrm{U}=124.5$; $\mathrm{p}=, 53$.

Tablica 4. Razina kvalitete identifikacije kliničkog problema i primjene odgovarajućih dokaza iz literature prema znanju o pretraživanju informacija

\begin{tabular}{llllllll}
\hline $\begin{array}{l}\text { Rezultat } \\
\text { 1. pitanju }\end{array}$ & Varijabla & \multirow{2}{*}{$\mathrm{M}$} & \multirow{2}{*}{ SD } & \multicolumn{2}{l}{ Min. Max. $\gamma_{1}$} & \multicolumn{1}{l}{$\kappa$} \\
\hline Nizak & Pitanje 4.a) & 2,36 & 0,497 & 2 & 3 & 0,53 & $-1,83$ \\
& Pitanje 4.i) & 2,29 & 0,611 & 1 & 3 & $-0,15$ & $-0,91$ \\
\hline \multirow{2}{*}{ Visok } & Pitanje 4.a) & 2,25 & 0,447 & 2 & 3 & 1,05 & $-0,95$ \\
& Pitanje 4.i) & 2,19 & 0,403 & 2 & 3 & 1,45 & 0,13 \\
\hline
\end{tabular}

Legenda: M - aritmetička sredina, SD - standardna devijacija, Min. - minimum, Max. - maksimum, $\gamma_{1}$ - koeficijent asimetričnosti, $\kappa$ - koeficijent spljoštenosti.

Kako bi se ispitao redoslijed prepreka ovisno o tome traje li staž kraće ili dulje od 10 godina, izračunate su frekvencije navođenja prepreka u svakoj od te dvije skupine. Te se frekvencije nalaze u Tablici 5. Tablica 5. Redoslijed prepreka prema duljini radnog staža

\begin{tabular}{|c|c|c|}
\hline Staž & Prepreka & $\mathrm{f}$ \\
\hline & Nedovoljno vremena koje osigurava uprava & 10 \\
\hline & Manjak interesa & 8 \\
\hline & Općeniti manjak rezultata istraživanja & 6 \\
\hline & Manjak organizacijskih uvjeta & 5 \\
\hline & $\begin{array}{l}\text { Nemogućnost primjenjivanja rezultata istraži- } \\
\text { vanja na pacijente s jedinstvenim karakteristi- }\end{array}$ & \\
\hline$<=10$ & kama & \\
\hline $\operatorname{godi}$ & Nedovoljno razumijevanje statističkih analiza & 3 \\
\hline na & Manjak istraživačkih vještina & 2 \\
\hline & $\begin{array}{l}\text { Manjak podrške između kolega na mom rad- } \\
\text { nom mjestu }\end{array}$ & \\
\hline & $\begin{array}{l}\text { Slaba sposobnost za kritičko prosuđivanje li- } \\
\text { terature }\end{array}$ & 2 \\
\hline & Manjak informacijskih izvora & 1 \\
\hline & Neprihvaćenost od kolega & 1 \\
\hline & Nedovoljno vremena koje osigurava uprava & 8 \\
\hline & Manjak organizacijskih uvjeta & 7 \\
\hline & Manjak informacijskih izvora & 6 \\
\hline & Manjak interesa & 5 \\
\hline & $\begin{array}{l}\text { Manjak podrške između kolega na mom rad- } \\
\text { nom mjestu }\end{array}$ & \\
\hline 10 & Nedovoljno razumijevanje statističkih analiza & 3 \\
\hline godi & Općeniti manjak rezultata istraživanja & 3 \\
\hline & Manjak istraživačkih vještina & 2 \\
\hline & $\begin{array}{l}\text { Slaba sposobnost za kritičko prosuđivanje li- } \\
\text { terature }\end{array}$ & \\
\hline & $\begin{array}{l}\text { Nemogućnost primjenjivanja rezultata istraži- } \\
\text { vanja na pacijente s jedinstvenim karakteristi- } \\
\text { kama }\end{array}$ & \\
\hline & Neprihvaćenost od kolega & 1 \\
\hline
\end{tabular}

Legenda: $f$ - frekvencija.

\section{RASPRAVA}

U istraživanju je sudjelovalo ukupno 14 muškaraca, od toga 9 u Mostaru i 5 u Puli te 16 žena, od toga 6 u Mostaru i 10 u Puli. U istraživanju su iz pulske bolnice sudjelovale samo osobe s preddiplomskim studijem radiološke tehnologije, dok je iz bolnice u Mostaru sudjelovalo po 7 sudionika s preddiplomskim studijem radiološke tehnologije i specijalizacijom u području radiologije te 1 sudionik s diplomskim studijem. Ovo istraživanje upućuje na činjenicu da je većina radiološkog osoblja obiju bolnica imala pozitivan stav prema radiologiji zasnovanoj na dokazima. Razumijevanje pojmova koji se koriste u radiologiji zasnovanoj na dokazima bilo je povezano s primjenom iste. Čak $60 \%$ ispitanika mostarske bolnice potvrdno je odgovorilo da su za vrijeme svog školovanja učili osnove za pretraživanje informacija o primjeni dokaza u praksi, dok je na isto pitanje u pulskoj bolnici potvrdno odgovorilo $46,67 \%$ ispitanika. $46,67 \%$ ispitanika obiju bolnica izjavili su da su prisustvovali obuci za pretraživanje istraživanja relevantnih struci. $\mathrm{U}$ usporedbi s istraživanjem Evidence-based practice in radiology: Knowledge, attitude and perceived barriers to practice among residents in radiology, Jacob i sur., (20) a koje je provedeno od strane Christian Medical College-a u Južnoj Indiji, jasno su vidljive razlike $\mathrm{u}$ rezultatima. U navedenom istraživanju samo je 5\% ispitanika izjavilo da su za vrijeme svog školovanja učili osnove za pretraživanje informacija o primjeni dokaza u praksi, te je $11 \%$ ispitanika pristupilo obuci za pretraživanje istraživanja relevantnih struci. 60 \% sveukupnih ispitanika je kao najveću prepreku u usavršavanju kliničke prakse s novim znanjem istaknula nedovoljno vremena koje osigurava uprava. U mostarskoj bolnici su manjak interesa svrstali na drugo mjesto, dok su u pulskoj bolnici smatrali da je druga prepreka po redu općeniti manjak rezultata istraživanja. U radu, Evidence-based practice in radiology, M. Dias i sur., provedenom 2013. godine u Portugalu, ispitanici su bili sličnog razmišljanja te su kao dvije najveće prepreke istaknuli nedovoljno vremena koje osigurava uprava te manjak interesa(24). Tijekom pripreme istraživanja, te usporedbe sa prethodnim istraživanjima koji su obuhvaćali radiologe 
kao uzorak, primijetili smo kako postoji malo istraživanja u području radiologije na ovu temu. Postoji puno smjernica i preglednih radova, ali istraživačkih radova sa konkretnim zaključcima nedostaje. Nedostaci ovog istraživanja bili bi nepovoljno vrijeme istraživanja (Covid 19), mali uzorak koji smo imali na raspolaganju u dvije bolnice, te nepostojanje neke vrste intervencije kojom bi konačno mogli ući u razloge zbog kojih su neki rezultati neočekivano lošiji. Preporuka za buduća istraživanja idu u smjeru obuhvaćanja veće populacije radiologa sa barem desetak medicinskih institucija. Ovaj rad može poslužiti, kako donositeljima odluka, tako i zdravstvenim djelatnicima u pružanju kvalitetnije zdravstvene zaštite, tako što će podići svijest o važnosti korištenja znanstveno utemeljenih dokaza u području biomedicine i zdravstva.

\section{ZAKLJUČAK}

Ispitali smo znanja, stavove i prepreke u praksi zasnovanoj na dokazima kod radiološkog osoblja $\mathrm{u}$ dvije zdravstvene institucije. Tijekom pripreme istraživanja, te usporedbe sa prethodnim istraživanjima koji su obuhvaćali radiologe kao uzorak, primijetili smo kako postoji malo istraživanja u području radiologije na ovu temu. Nismo pronašli značajne razlike prepreka primjene prakse zasnovane na dokazima u radiologiji između Kliničkog zavoda za radiologiju Sveučilišne kliničke bolnice Mostar i Odjela za radiološku dijagnostiku Opće bolnice Pula.

Ovo istraživanje upućuje na činjenicu da je većina radiološkog osoblja obiju bolnica imala pozitivan stav prema radiologiji zasnovanoj na dokazima. Razumijevanje pojmova koji se koriste u radiologiji zasnovanoj na dokazima bilo je povezano s primjenom iste.

\section{LITERATURA}

1. Marušić M. i suradnici. Uvod u znanstveni rad u medicini. Zagreb: Medicinska naklada, 2013.

2. Tepšić M, Šimić J, Čotić K, Čupić M. Važnost istraživanja i prakse utemeljene na dokazima za sigurnost bolesnika i kvalitetu zdravstvene njege. Zdravstveni glasnik. 2019;5(2):95-101.
Pristupljeno na https://hrcak.srce.hr/228918 (20.09.2020.)

3. Krleža-Jerić, K., Gabelica M, Banzi R, Krnić-Martinić M, Pulido B, Mahmić-Kaknjo M,Reverie L, Šimić J, Utrobičić A, Hrgović I. IMPACT Observatory: tracking the evolution of clinical trial data sharing and research integrity. Biochemia Medica. 2016;26:308-17.

4. Šimić J, Babić D. Znanstvena komunikacija u biomedicini i zdravstvu. Zdravstveni glasnik. 2018;2:68-70. Pristupljeno sa: https://fzs. sum.ba/sites/default/files/Glasnik\%202-2018. pdf\#page $=70$ (19.09.2020.)

5. McColl A, Smith H, White P, Field J. General practitioner's perceptions of the route to evidence based medicine: a questionnaire survey. BMJ 1998;316 (7128):361-5.

6. Straus SE, Richardson WS, Glasziou P, Haynes RB. Evidence-based medicine: how to practice and teach EBM. 3. izd. Edinburgh: Elsevier Churchill Livingstone; 2007.

7. Balas EA, Boren SA. Managing clinical knowledge for healthcare improvements. Yearbook of medical informatics 2000.:

8. Hafslund B, Clare J, Graverholt B, Wammen Nortvedt M. Evidence-based radiography. Radiography 2008; 14: 343 - 348.

9. Evidence-Based Radiology Working Group. Evidence-based radiology: a new approach to the practice of radiology. Radiology 2001.; 220: 566-575

10. Imhof H. Stellung und Einbindung der Radiologie in einem Großklinikum. Radiologe 2005;45:319-326.

11. Blackmore CC. Evidence-based imaging in trauma radiology: where we are and how to move forward. Acta Radiologica 2009.; 50: 482-489.

12. Kelly AM. Evidence-based radiology: step 1 ask. Seminars in Roentgenology 2009; 44: 140146.

13. Puig S, Felder-Puig R. Evidenzbasierte Radiologie: Ein neuer Ansatz zur Bewertung von klinisch angewandter radiologischer Diagnostik und Therapie. Fortschr Röntgenstr 2006; 178: 671-679. 
14. Ng CKC, White P, McKay JC. Establishing a method to support academic and professional competence throughout an undergraduate radiography programme. Radiography. 2007; 14: 255-264.

15. Eddy A. Advanced practice for therapy radiographers - A discussion paper. Radiography. 2006; 14 ; 24-31.

16. Jackson C. Assessment of clinical competence in therapeutic radiography: A study of skills, characteristics and indicators for future career development. Radiography. 2007; 13:147-158.

17. Estabrooks CA, Chong H, Brigidear K, Profetto-McGrath J. Profiling Canadian nursespreferred knowledge sources for clinical practice. Can J Nurs Res 2005;37:1840.

18. Flores-Mateo G, Argimon JM. Evidence Based Education in Postgraduate Health Care: A Systematic Review. BMC Health Services Research.2007; 7: 119.

19. Forsetlund L, Bjorndal A. Identifying barriers to use of research faced by public health physicians in Norway and developing an intervention to reduce them. J Health Serv Res Policy 2002;7:10-18.
20. Jacobb K. S., Shyamkumar N. K., Gibikote S. Evidence-based practice in radiology: Knowledge, attitude and perceived barriers to practice among residents in radiology. European Journal of Radiology 2013.;82: 894-897.

21. McCaughan D, Thompson C, Cullum N, Sheldon TA, Thompson DR. Acute care nursese perceptions of barriers to using research information in clinical decisionmaking. J Adv Nurs 2002;39:46-60.

22. van Beek EJ. From teacher to student centered education: theory and practical application in evidence-based radiology [master's dissertation]. Sheffield, England: University of Sheffield; 2004.

23. van Beek EJ, Malone DE. Evidence-based practice in radiology education: why and how should we teach it? Radiology 2007;243:633-640.

24. M. Dias, Costa1 C, Abrantes1 AF, Ribeiro1 LP, Azevedo1 KB. Evidence-based practice in radiology: the radiographer perspective. Algavre: Medical Imaging and Radiotherapy, School of Health - University of Algavre; 2017; B-0823; $1-12$. 


\title{
EVIDENCE-BASED PRACTICE IN RADIOLOGY: ATTITUDES AND KNOWLEDGE OF HEALTH CARE PROFESSIONALS
}

\author{
Martina Jurilj, Ana Jerković, Josip Šimić \\ Faculty of Health Studies University of Mostar
}

\begin{abstract}
Introduction: Evidence-based practice in radiology is the integration of the best research evidence into radiology practice. Objective: The objective of this study is to investigate the differences in knowledge and attitudes and identify the difference in the restrain of applying evidence-based practice in radiology at the Clinic for Radiology of the University Clinical Hospital Mostar and Department for Diagnostic Radiology of the Pula General Hospital.

Subjects and methods: The subjects of the study are bachelors and masters of radiologic technology and physicians specialists of radiology. We used a self-administrated questionnaire. A cross-sectional study was conducted at the University Clinical Hospital Mostar at the Clinical for Radiology and the Pula General Hospital the Department for Diagnostic Radiology.

Results: The results point to the fact that most radiology staff at both hospitals have a positive attitude toward evidence-based radiology. Understanding of terms used in evidence-based radiology is associated with its application. As many as $60 \%$ of subjects from the University Clinical Hospital Mostar answered that during their university education they learned the basics for information seeking on the application of evidence in practice, and $46.67 \%$ subjects from the Pula General Hospital had the same affirmative answer.

Conclusion: The majority of radiology staff have a positive attitude toward evidence-based radiology. The application of evidence-based medicine binds individual clinical observations and experiences with the best scientific evidence obtained by clinical research.
\end{abstract}

Key words: attitudes, knowledge, radiology, evidence-based practice

Correspondence:

Ana Jerković, Master of radiologic technology

E-mail: ajerkovic97@gmail.com 